\title{
Provision of artificial warrens as a means to enhance native wild rabbit populations: what type of warren and where should they be sited?
}

\author{
Mariana Fernández-Olalla • María Martínez-Jauregui • \\ Francisco Guil - Alfonso San Miguel-Ayanz
}

\begin{abstract}
In Spain, wild rabbits are essential for some highly endangered species, and, therefore, many actions have been undertaken to increase their populations. In the present study, artificial warrens are provided as a means to increase shelter for native wild rabbit populations in a given area. We cvaluate the use of three types of warrens by rabbits and the effect on that use of five habitat characteristics at two spatial scales (500 $\times 500-\mathrm{m}$ grids and $25-\mathrm{m}$ plots). To cvaluate that usc, wc identified pre-cstablished signs at the entrances to each warren, and based on this, we calculated occupancy rate and activity. Our results indicate that rabbit abundance within a grid is the only variable which simultaneously explains both the greater occupancy and the higher activity in the artificial warrens located in that grid. Some $73.2 \%$ of the grids showed signs of rabbit use at the time of the evaluation. However, the pre-existing rabbit populations within the grids were not quantified and, hence, we cannot state that the warrens contributed to an increase in the rabbit abundance. Regarding the habitat, our results reveal that warrens should be situated in grids with food coverage of less than $50 \%$, while the use of each individual refuge is greater where food availability in the immediate surroundings is at least $20 \%$ and shelter at least $50 \%$. The tube warrens showed significantly greater rabbit use
\end{abstract}

than the other types while there was little difference between the stone and pallet warrens in terms of use.

Keywords Habitat management - Mediterranean ccosystems - Oryctolagus cuniculus $\cdot$ Risk of predation · Shelter

\section{Introduction}

The wild rabbit (Oryctolagus cuniculus) is native to the lberian Peninsula, where its populations have thrived successfully since the Palaeolithic period (Branco et al. 2002). However, in recent decades, they have dramatically declined in large areas, mainly due to myxomatosis and rabbit haemorrhagic disease (Delibes-Mateos et al. 2009). A sharp population decrease of $71 \%$ from 1973 to 1993 has been documented (Virgós et al. 2007). The conservation of this species is of great relevance for the Mediterranean region: it is considered both a keystone species and an ecosystem engineer in southern Europe (Delibes-Mateos et al. 2008a; Gálvez-Bravo et al. 2009). Additionally, the rabbit is an important small game species in Spain, and the profit obtained from hunting can contributc significantly to the cconomy in rural arcas (Delibes-Mateos et al. 2008b).

Over the last few years, many strategies have been developed to increase wild rabbit populations in Spain, often with the final aim of recovering the populations of Iberian lynx (Lynx pardinus), Spanish imperial eagle (Aquila adalberti) or cinereous vulture (Aegypius monachus) within the framework of projects supported by LIFE funds (European Commission LIFE-Projects). Current work centres around drawing conclusions from the valuable initiatives undertaken to date in order to develop appropriate conservation strategies and optimise the existing funds. 
Apart from the release of animals, in the form of either restocking or translocation, the most widespread strategies for the recovery of rabbit populations involve habitat management. Basically, these techniques consist of improving the carrying capacity of a habitat, by increasing the availability of food, shelter or both (Cabezas and Moreno 2007; Delibes-Mateos et al. 2009).

Natural shelter can be easily increased by building artificial warrens. These warrens provide safe places where rabbits can breed and find refuge from predators, since predation could prevent the recovery of rabbit populations in Mediterranean ecosystems, especially in places where rabbits are at low densities (the predator-pit hypothesis, Pech et al. 1992; Palomares et al. 1996; Delibes-Mateos et al. 2009).

Although the installation of artificial warrens is a commonly used strategy in Spain in both protected zones and hunting areas, little is known about how the characteristics of the location and the type of warren affect the extent of utilisation by wild rabbits.

In this paper, we study the installation of artificial warrens as a stand-alone measure to boost native rabbit populations. The degree of use of the artificial warrens by the rabbits was estimated via latrine counts at warrens entrances and was analysed through the variables "occupancy and activity". We had four specific objectives: (1) to estimate the amount of use of the warrens by the rabbits; (2) to identify the better locations at larger spatial scales; (3) to determine which type of artificial warren should be installed and finally, (4) to decide where to place each artificial warren at smaller spatial scales. That way, we expect to provide the managers with a simple protocol of how to undertake this strategy.

\section{Materials and methods}

Study area

The study was carried out on 14 private estates located in the provinces of Toledo (4), Cáceres (1), Badajoz (2), Ciudad Real (1) and Albacete (6) in central Spain (Fig. 1). All the estates were included in LIFE-projects to enhance their rabbit populations and, therefore, to ensure the conservation of the endangered species present there. In terms of the criteria, which most affect wild rabbit abundance and population trends (natural and management factors) all the estates can be considered relatively homogeneous (Delibes-Mateos et al. 2009).

Type of artificial warrens

No rabbits were released into the artificial warrens. Figure 2 shows sketches of each type of warren. The distribution of all three types of warren according to estate and region is shown in Table 1. The warrens were built between 2002 and 2006 and were located in areas where remnant wild rabbit low-density populations existed. Once the experimental sites on the estates had been chosen, all of the artificial warrens within each individual estate were established simultaneously. The warrens were located in

Fig. 1 Location of estates and regions in the study area. Extremadura $=$ estates $1-3$; Sierra Morena $=$ estates $4-10$, Montes de Toledo $=$ estates $11-14$

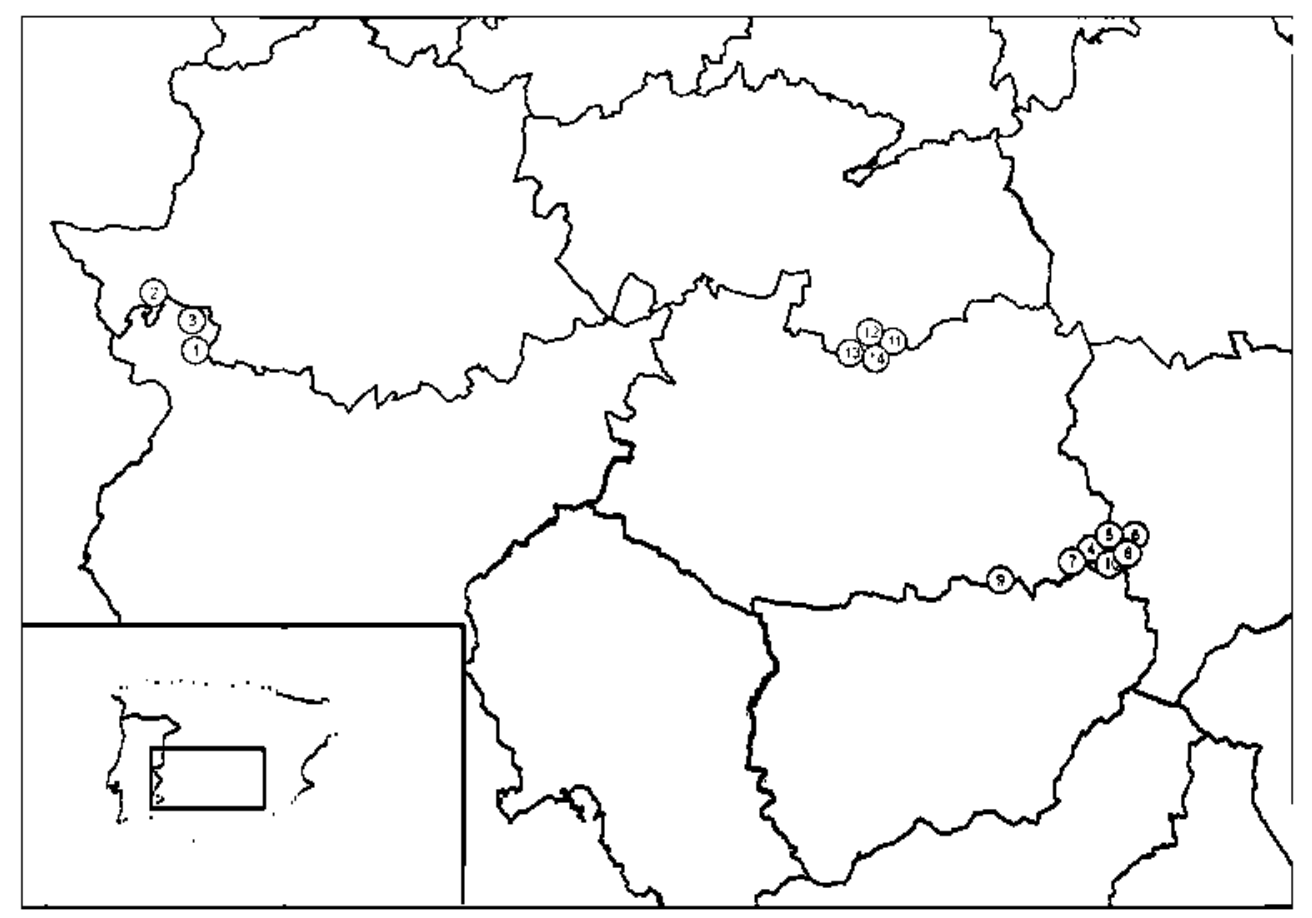


Fig. 2 Side and top views of the different types of warren used in the study

\section{StoneWarren}

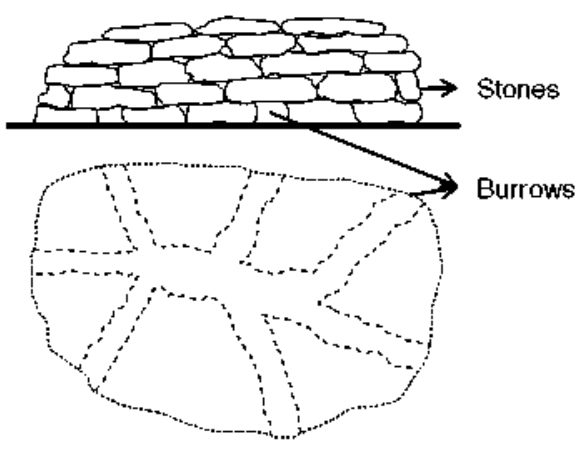

Pallet Warren
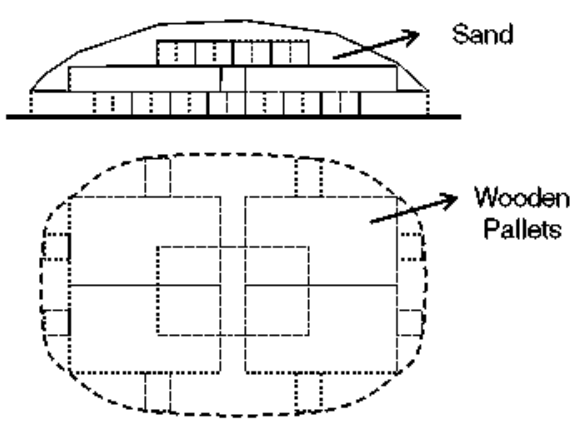

Tube Warren
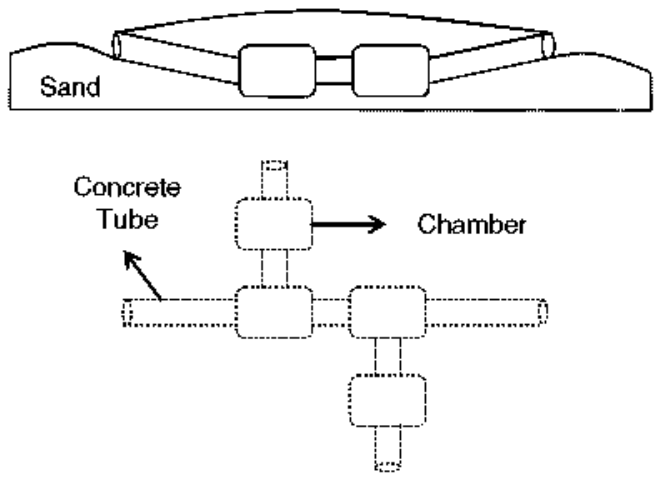

places of similar characteristics to those where, according to previous studies (Palomares 2003; Gea-Izquierdo et al. 2005), rabbits would locate their natural warrens. Three types of warren were chosen for the following reasons: (1) stone warrens are widespread and have been used in the Spanish countryside for many years; (2) pallet warrens are inexpensive, easy to install and biodegradable and (3) tube warrens are those which are most similar to the natural warrens described by Kolb (1985) and may therefore be preferred by rabbits.

The number of warrens built differed from one estate to another, and the total number was 525 (207 stone, 198 pallet and 120 tube warrens; Table 1).

- Stone warrens. These were built using stone material obtained from the estates. They had a circular form
Table 1 Estate description

Tube, stone and pallet refer to the number of tube, stone and pallet warrens built. Year refers to the warren years of installation and Grids to the number of grids $(500 \times 500 \mathrm{~m})$ with artificial warrens within each estate. Mean refers to the mean value of wartens per grid in each estate. In the bottom line, it is included the total number of grids and warrens of each type studied, respectively, and, in the last cell, the mean \pm standard deviation of the number of artificial wartens per grid and state

\begin{tabular}{lllllllll}
\hline Region & Province & Estate & Year & Grids & Tube & Stone & Pallet & Mean \\
\hline Extremadura & Badajoz & 1 & 2003 & 2 & 9 & 21 & & 15.00 \\
& Cáceres & 2 & 2002 & 3 & 15 & 19 & & 11.33 \\
& Badajoz & 3 & 2004 & 2 & & & 14 & 7.00 \\
Sierra Morena & Albacete & 4 & 2003 & 19 & & 18 & 125 & 7.53 \\
& Albacete & 5 & 2005 & 6 & & 18 & 4 & 3.67 \\
& Albacete & 6 & 2005 & 3 & 26 & & & 8.67 \\
& Albacete & 7 & 2005 & 4 & 13 & & & 3.25 \\
& Albacete & 8 & 2006 & 4 & & 11 & & 2.75 \\
& Ciudad Real & 9 & 2004 & 2 & & 16 & & 8.00 \\
& Albacete & 10 & 2005 & 19 & 5 & 20 & 42 & 3.53 \\
Montes de Toledo & Toledo & 11 & 2005 & 11 & 48 & & & 4.36 \\
& Toledo & 12 & 2005 & 7 & & 46 & & 6.57 \\
& Toledo & 13 & 2006 & 3 & & & 13 & 4.33 \\
& Toledo & 14 & 2005 & 13 & 4 & 38 & & 3.23 \\
& & & Totals & 98 & 120 & 207 & 198 & $6.37 \pm 3.56$ \\
\hline
\end{tabular}


(approximately $5 \mathrm{~m}$ in diameter) and between six and ten entrances. First, the base stones were set starting from the centre, leaving galleries and holes between them, and finally the entire structure was covered with another layer of stones.

- Pallet warrens. Each warren consisted of a minimum of four wooden pallets similar to those used for transportation. The sides and top were subsequently covered with stones, leaving four to eight holes as entrances.

- Tube warrens. A complete description of this type of warren can be found in González and San Miguel (2004). These warrens were made of concrete tubes ( $15 \mathrm{~cm}$ in diameter and $1 \mathrm{~m}$ in length) connected by central PVC bottomless chambers simulating a labyrinth. The whole structure was placed underground (approximately $1 \mathrm{~m}$ depth) and was subsequently covered with sand. All tube warrens studied had four entrances.

A tube warren costs around $250 €$, a stone warren $240 €$ and a pallet warren $180 €$ (CBD-Habitat Foundation unpublished data), although the final price of establishing a warren on an estate could vary widely, depending on material transport costs.

\section{Data collection}

Data were collected during February and March of 2007. Two spatial scales were established in order to obtain as much information as possible about where to locate a set of artificial warrens and where to place each individual warren. Every set of artificial warrens on each estate was divided into $500 \times 500-\mathrm{m}$ grids (according to the UTM coordinate system). Although the grids in each estate were fairly homogeneous, we also characterised the microhabitat around each warren to assess whether small differences in habitat characteristics affected the level of warren use. We defined circular plots with a $25-\mathrm{m}$ radius around the central point of every artificial warren.

In each grid, we estimated rabbit abundance using a relative abundance index (RAI). It was measured through latrine counts made walking along fixed transects which crossed each grid. This method provides a good indirect measure of rabbit abundance in this type of large-scale studies (Palomares 2001). The index was expressed as the number of latrines per kilometre, and we used it to correct for the different rabbit abundances in each grid.

The type of artificial warren was defined as a categorical variable with three levels: stone, pallet and tube. Each artificial warren was evaluated through its entrances. The entrances were given a "score" according to pre-established rabbit activity signs (Table 2), as described by Muñoz (2005). On the basis of the scores, we obtained the dependent variables for the statistical analyses. We calcu- lated the "average warren activity" variable, which was the average score for the entrances to a given warren and the "average grid activity", which was the average score for all the warrens located in a grid. As these two activities had many zero values, each variable was redefined into two, as proposed by Fletcher et al. (2005). On the basis of the average warren activity, we defined warren occupancy $\left(O_{\mathrm{w}}\right)$ as a binary variable describing whether the average activity was zero (not occupied) or one (occupied). The warren activity $\left(A_{\mathrm{w}}\right)$ included only positive values of average warren activity. In the same manner, we determined grid occupancy $\left(O_{\mathrm{g}}\right)$ and grid activity $\left(A_{\mathrm{g}}\right)$.

Finally, four environmental variables (soil, suitable food, suitable shelter and water sources) were measured at microand macrohabitat scales, whereas topography was measured only at microhabitat level, since the topography of each of the grids was similar and fairly flat. Table 2 includes a description of these variables.

\section{Statistical analysis}

Two analyses of variables at macrohabitat scale and two analyses of the variables at microhabitat scale were performed. We used "R.2.8.0" software (R Development Core Team 2008) for the analysis.

In the macrohabitat analyses, the individual grid was the experimental unit. To evaluate factors influencing grid occupancy, we used a generalised linear mixed model with a log-link function and a binomial distribution (Crawley 2007). RAI, number of years since warrens construction and number of artificial warrens per grid were included as covariates. Fixed factors were soil, shelter, food, water sources and their first-order interaction. Regions were introduced as a random factor (Analysis MAC1). Additionally, we fitted a general linear mixed model to determine whether any natural characteristic of a grid entails higher levels of activity in the warrens located within it. The response variable was $\log \left(A_{g}\right)$. The covariates, fixed and random factors were the same as in the previous model (Analysis MAC2).

In the microhabitat analysis, the individual artificial warren was the experimental unit. Similarly, a generalised linear mixed model was fitted for the response variable $O_{\mathrm{w}}$. We included type of warren, topography, soil, shelter, food and water, as fixed factors taking into account their firstorder interaction. Regions and grids within regions were included as random factors (Analysis MIC1). A general linear mixed model was also carried out for the response variable $\log \left(A_{\mathrm{w}}\right)$, using the same fixed and random factors as in the previous model (Analysis MIC2).

The generalised linear mixed models were fitted using the Laplace approximation, and the general linear mixed models were fitted using the maximum likelihood method 
Table 2 Habitat variables (above) and activity levels for artificial warten entrance evaluation (below)

\begin{tabular}{|c|c|c|}
\hline & Variable/level & Description \\
\hline \multirow[t]{5}{*}{ Habitat variables } & Soil & $\begin{array}{l}\text { Binary variable indicating whether rabbits were able to dig } \\
\text { the predominant soil in each plot. Level } 0=\text { hard soil } \\
\text { (tertiary alluviums, such as the raña formations, slate based } \\
\text { soils and quartzite based soils), } 1=\text { soft soil (quaternary } \\
\text { alluviums, arkose and granitic soils) }\end{array}$ \\
\hline & $\begin{array}{l}\text { Suitable food (subsequently } \\
\text { referred to as "Food") }\end{array}$ & $\begin{array}{l}\text { Categorical variable whose levels (high, medium and low) } \\
\text { depended on the percentage of cover that was suitable for } \\
\text { feeding ( }>50 \%, 50-20 \% \text { and }<20 \% \text {, respectively). }\end{array}$ \\
\hline & $\begin{array}{l}\text { Suitable shelter (subsequently } \\
\text { referred to as "Shelter") }\end{array}$ & $\begin{array}{l}\text { Categorical variable with three levels (high, medium and low), } \\
\text { similarly to levels defined for the food variable }\end{array}$ \\
\hline & Water sources & $\begin{array}{l}\text { Binary variable describing the presence or absence of water } \\
\text { sources in the plot (gullies, streams, ponds or artificial } \\
\text { drinking sources) }\end{array}$ \\
\hline & Topography & $\begin{array}{l}\text { Categorical variable describing the location of the artificial } \\
\text { warren as top, hillside, foot (lower part of the hillside), } \\
\text { valley bottom or flat }\end{array}$ \\
\hline \multirow[t]{5}{*}{ Activity levels at entrances } & 0 & $\begin{array}{l}\text { No activity. No signs of use are present. No faeces and no } \\
\text { marking. Existence of spider webs }\end{array}$ \\
\hline & 1 & $\begin{array}{l}\text { Low activity. Not sure if rabbits use the entrance. Some old } \\
\text { faeces (brown, absence of green mucous covering and black) } \\
\text { or badly preserved }\end{array}$ \\
\hline & 2 & $\begin{array}{l}\text { Medium activity. Some droppings, fresh (greenish, presence of } \\
\text { mucous covering) or almost fresh (black, consistent). Never } \\
\text { more than } 15 . \text { There are diggings nearby }\end{array}$ \\
\hline & 3 & $\begin{array}{l}\text { High activity. Many fresh or almost fresh faeces } \\
\text { (approximately } 15-40 \text { ), though no large latrines. }\end{array}$ \\
\hline & 4 & $\begin{array}{l}\text { Maximum activity. Many fresh or almost fresh faeces }(>40) \text {; } \\
\text { well marked passage. }\end{array}$ \\
\hline
\end{tabular}

(Crawley 2007). In all cases, the models were simplified by removing non-significant factors $(\alpha=5 \%)$ after checking that the simplification did not significantly change the model. Once we had determined the significant factors in each model, we subsequently aggregated the nonsignificant levels of each factor to obtain the "minimal adequate model", using a stepwise a posteriori procedure. If two levels of a factor did not differ significantly and did not improve the fit of the model, they were grouped together (Crawley 2007). Model comparisons were carried out using likelihood criteria.

\section{Results}

Data were collected from 98 grids. In 72 of the grids $(73.47 \%)$, the artificial warrens showed signs of rabbit use at the time the data were collected. The 26 remaining grids showed no rabbit use in any artificial warrens, although 15 of them have rabbit populations currently. The fact that the artificial warrens in a given grid are not used by rabbits may be due to other factors and not to the absence of rabbits in that grid. We found an average of 3.16 latrines $/ \mathrm{km}$ (range, $0.00-$ $14.80 ; \mathrm{SE}, 3.89$ ) in grids where the warrens showed no sign of use and an average of 13.49 latrines $/ \mathrm{km}$ (range, $0.00-90.00$; SE, 14.67) in grids where warrens had been used by rabbits.

In Appendix 1, we have included models MACl, $\mathrm{MAC} 2, \mathrm{MIC} 1$ and $\mathrm{MIC} 2$ after the simplification of nonsignificant factors but before the simplification of nonsignificant levels of the factor, to fit the minimal adequate models in each case. To facilitate the interpretation of the results, only the results of the minimal adequate model are referred to in the text. The first-order interactions of fixed effects were not significant in any of the models.

In MAC1, the only significant variable was rabbit RAI ( $p=0.0021$ ), showing a positive relationship with warren occupancy in each grid. The same relationship $(p=0.0225)$ was observed in MAC2, which also revealed that warrens located in soft soils grids $(p<0.001)$ and with medium to high levels of food (coverage $>20 \% ; p=0.0111$ ) had significantly higher rabbit activity.

We found that the inclusion of grids nested in regions significantly improved the models, both in the case of MICl $(p<0.001)$ and MIC $2(p<0.001)$. The only significant effect in MIC 1 was the type of warren. Tube warrens showed the highest occupancy rates (occupancy rate $=0.6743$ ), differing significantly from the other two types (occupancy rate $=0.5388 ; p<0.001$ ). 
Significant factors in MIC2 were type of warren, food and shelter. Topography was found to be not significant at 5\% (see Appendix 1), but its elimination brought about significant changes to the model, hence it was retained (Likelihood ratio test $=10.84$ model without/with factor topography, $p=0.0283$ ). The minimal adequate model for MIC2 showed that the tube warrens were those with the highest activity levels, again differing from the other two $(p<0.001)$ that did not differ between them. The warrens surrounded by medium to high levels of food and high levels of shelter were significantly $(p<0.001)$ more used by rabbits than those with low level of food coverage and low to medium levels of shelter, respectively. The sign of the coefficients estimated in MIC2 for topography levels suggested that locations at the foot of hillsides could show lower rabbit activity (negative sign). We repeated the last model but grouping topography levels (foot hillside versus the others). This did not lead to significant changes in the model (Likelihood ratio test $=$ 0.7365 model grouped/non-grouped topography levels, $p=$ 0.8646) and furthermore, the new two-level factor was found to be significant ( $p=0.0017$ ), indicating that warrens located at the foot of the hillsides showed lower degrees of activity. Water sources and soil type had no significant effect either in MIC 1 or in MIC 2.

\section{Discussion}

In this study, we used a scale beyond that of the estate (region) which could be particularly useful for endangered species management, since their territories extend beyond the limits defined by these private properties. However, at such a large-scale and without previous information about good management practices regarding artificial warrens, it was far out of our reach to cover every possible environmental situation with a suitable experimental design. Besides, our results should be interpreted with caution, since the effect of building artificial warrens on wild rabbit densities has not been quantified. It would be necessary to deal with this topic in depth in further studies. That is why our contribution could be regarded as a first step in a suitable direction since it has been able to satisfactorily fulfil its specific objectives.

The first question was to ascertain whether artificial warrens were significantly used by sparse wild rabbit populations. The answer is positive since, in spite of the abovementioned limitations, a high percentage of those warrens were used by wild rabbits. Our results also indicate that at larger scales, rabbit abundance within a grid is a fundamental variable to explain the degree of rabbit use of the artificial warrens located in that grid, even though it showed large standard deviations between the grids (Fa et al. 1999; Calvete et al. 2004). The warrens situated in areas with greater rabbit abundance show higher rates of occupancy and activity. We suggest two possible reasons for this: (1) the requirement of a previous minimal rabbit population in the area where the artificial warrens were placed in order to serve as a founding population and (2) higher refige availability resulting in higher rabbit population densities (Catalán et al. 2008), since this minimises the impact of predation and provides better breeding areas. The first practical conclusion which can be drawn is that, where possible, artificial warrens should be sited in areas with existing rabbit populations, although low, but as large as possible. However, it is remarkable that half of the grids where rabbits did not use warrens did have, indeed, wild rabbit populations. We found that other macrohabitat variables, such as soil type and food coverage, also affect that use.

Previous studies demonstrated that wild rabbit distribution and their overall abundance are related to soil type and climate at large scales and to the availability of food and shelter at smaller scales (Fa et al. 1999). What is more, Cabezas and Moreno (2007) found that food availability was the prime factor regulating rabbit densities and that this factor, together with the availability of shelter; was a fundamental factor in the success or failure of rabbit translocation initiatives. Our results also reveal a relationship between higher rabbit activity in the artificial warrens and food coverage at grid scale and with food coverage and shelter at smaller scales. However, we expected to find higher levels of use in artificial warrens located on soils where rabbits could not dig their own warrens (Gea-Izquierdo et al. 2005; Williams et al. 2007). On the contrary, our results indicate that artificial warrens in soft soil grids were more used by the species. This may be related to the fact that it is precisely in these areas of diggable soils where stable populations of wild rabbit could have remained and, therefore, significantly use more the artificial warrens. The effect of soil type in warren level of activity in grids can be, thereby, an indirect effect related to higher rabbit abundance, as well as could happen with food coverage at grid scale.

Regarding the habitat surrounding each individual warren, our results indicate that rabbits select warrens surrounded by food coverage of at least $20 \%$ and shelter coverage of at least $50 \%$. The fact that the most used warrens were surrounded by a mix of food and shelter coverage fits in with the ecotone preference theory. Rabbits usually select ecotones between pasturelands and scrublands because they can obtain both shelter and food in these environments (Rogers and Myers 1979), although Lombardi et al. (2003) also found a higher incidence of predation and disease in these areas. The artificial warrens with low to medium shelter coverage are less used by the rabbit, probably because the species would not even be able to colonise the warrens due to the high risk of predation or because, even if they were able to settle in the warrens, 
they could not satisfy their needs outside without being preyed upon. Strategies that minimise predation risk are crucial to a prey species like the wild rabbit, particularly when population levels are low (Palomares et al. 1996).

Only artificial warrens located at the foot of hillsides are less used by rabbits, probably because they are more susceptible to flooding than warrens in the other locations. It has been shown that the worst places for wild rabbits to breed are those susceptible to floods (Palomares 2003); thus, they conspicuously avoid these areas (Lombardi et al. 2007). Although none of the artificial warrens was found flooded at the time that data were collected, our experience indicates that the sites at the foot of hillsides are very prone to flooding, particularly if they are placed on plastic/impermeable soils (CBDFoundation, unpublished data).

Finally, wild rabbits seem to prefer tube warrens: they showed higher rates of occupancy and activity. Of the three types of warrens studied, this is the only underground type and, apparently, the one which most resembles the natural warrens so this result was to be expected. It is also very safe, as concrete tubes are impregnable to predators and the rabbits are able to create new galleries from the intermediate PVC bottomless chambers in the warren. The main disadvantage of this type of warren is that it is more susceptible to flooding than the other types (CBD-Habitat Foundation, unpublished data), so the location should be carefully chosen.

In conclusion, the artificial warrens have been widely used by sparse wild rabbit populations. Warrens should be located in areas with a minimum pre-existing rabbit population, soft soils and adequate food coverage. When choosing the location for each individual warren, the availability of food and shelter should be taken into consideration (food coverage $>20 \%$ and shelter $20-50 \%$; however, the presence of water sources does not seem to be necessary. We also recommend avoiding areas at the foot of hillsides and other places where flooding is possible. Considering the figures we deal with in this study, we have not found a relationship between the number of warrens per grid and warren use. We have identified, therefore, a number of management guidelines applicable to large-scale future initiatives involving artificial warrens. That way we would like to contribute to provide what many investigators and managers often miss: detailed advice on methodologies to recover wild rabbit populations, especially where needed for endangered predators conservation (Delibes-Mateos et al. 2008c).

Acknowledgements This study was carried out in the framework of the LIFE 2003/NAT/E/0050 and LIFE 2002/NAT/E/8617 projects. The artificial warrens were built by people of CBD-Habitat foundation. We are indebted to R. Higuero, A. Arredondo, L. Bolonio, M. Mata and J.F. Leiva for their help with fieldwork. The Environmental Spanish Ministry and the Royal Spanish Federation of Hunting also participated in the projects, as well as the Organismo Autónomo de Espacios Naturales of the regional government of Castilla-La Mancha and the Direccion General de Medio Ambiente of the regional government of Extremadura. We would like to thank to Victor Diez, Nacho Mosqueda, Antonio Aranda, Ramón Pintado and Javier Caldera, to the estate owners as well as those people from the CBDHabitat foundation who lent their assistance, especially $\mathrm{J}$. Oria, $\mathrm{S}$. Agudin, F. Silvestre, J. Inogés and J. Muñoz-Igualada. The authors would also like to express sincere thanks to Mar Celada, who translated the manuscript, to R. Perea and C. Herruzo for their useful comments on earlier drafts and to two anonymous referees and to $\mathrm{W}$. Lutz for their helpful suggestions.

\section{Appendix 1}

Table 3 Dependence of grid occupancy (MAC 1), grid activity (MAC2), warrens occupancy (MIC1) and warren activity (MIC2) on the predictor variables. Models are included after the removal of non-significant factors

\begin{tabular}{lllll}
\hline & Fixed factors level & Effects \pm SE & z value & P \\
\hline MAC 1 & Intercept & $-0.0116 \pm 0.3338$ & -0.0348 & 0.9722 \\
& RAI & $0.1629 \pm 0.0528$ & 3.0814 & 0.0021 \\
MIC 1 & Intercept & $1.2332 \pm 0.9052$ & 1.3620 & 0.1731 \\
& Type (stone) & $-1.8252 \pm 0.5572$ & -3.2750 & 0.001 \\
& Type (pallet) & $-2.4718 \pm 0.6431$ & -3.8440 & $<0.001$
\end{tabular}


Table 3 (continued)

\begin{tabular}{|c|c|c|c|c|c|}
\hline & Fixed factors level & Effects $\pm S E$ & DF & t value & $\mathrm{P}$ \\
\hline \multirow[t]{5}{*}{ MAC 2} & Intercept & $-0.7170 \pm 0.2780$ & 65 & -2.5786 & 0.0112 \\
\hline & RAI & $0.0146 \pm 0.0063$ & 65 & 2.3370 & 0.0225 \\
\hline & Soil (soft) & $0.6856 \pm 0.1836$ & 65 & 3.7333 & $<0.001$ \\
\hline & Food (medium) & $-0.6861 \pm 0.2952$ & 65 & -2.3244 & 0.0232 \\
\hline & Food (high) & $-0.7321 \pm 0.2862$ & 65 & -2.5577 & 0.0129 \\
\hline \multirow[t]{11}{*}{ MIC 2} & Intercept & $-0.0238 \pm 0.3027$ & 215 & -0.0786 & 0.9374 \\
\hline & Type (stone) & $-0.7423 \pm 0.1634$ & 215 & -4.5435 & $<0.001$ \\
\hline & Type (pallet) & $-0.7149 \pm 0.1725$ & 215 & -4.1444 & $<0.001$ \\
\hline & Food (medium) & $0.5643 \pm 0.1352$ & 215 & 4.1732 & $<0.001$ \\
\hline & Food (high) & $0.5951 \pm 0.1477$ & 215 & 4.0279 & $<0.001$ \\
\hline & Shelter (medium) & $-0.1369 \pm 0.1049$ & 215 & -1.3041 & 0.1936 \\
\hline & Shelter (high) & $0.3277 \pm 0.1502$ & 215 & 2.1813 & 0.0302 \\
\hline & Topo (hillside) & $0.0333 \pm 0.2526$ & 215 & 0.1317 & 0.8953 \\
\hline & Topo (foot) & $-04719 \pm 0.2903$ & 215 & -1.6253 & 0.1056 \\
\hline & Topo (valley bottom) & $0.1529 \pm 0.2886$ & 215 & 0.5299 & 0.5967 \\
\hline & Topo (flat) & $0.0865 \pm 0.2588$ & 215 & 0.3342 & 0.7385 \\
\hline
\end{tabular}

Effects \pm SE were calculated considering the reference value of zero for TYPE (tube), SOIL (hard), FOOD and SHELTER (low), TOPOGRAPHY (top). None of the first-order interaction was significant. Generalised linear mixed models (MAC 1 and MIC 1) were fitted using Laplace approximation and general linear mixed models (MAC 2 and MIC 2) using maximum likelihood criteria.

\section{References}

Branco M, Monnerot M, Ferrand N, Templeton AR (2002) Postglacial dispersal of the European rabbit (Orvctolagus cuniculus) on the Iberian Peninsula reconstructed fiom nested clade and mismatch analyses of mitochondrial DNA genetic variation. Evolution 56 (4):792-803

Cabezas S, Moreno S (2007) An experimental study of translocation success and habitat improvement in wild rabbits. Anim Conserv $10: 340-348$

Calvete C, Estrada R, Angulo E, Cabezas-Ruiz S (2004) Habitat factors related to wild rabbit conservation in an agricultural landscape. Landsc Ecol 19:531-542

Catalán I, Rodríguez-Hidalgo P, Tortosa FS (2008) Is habitat management an effective tool for wild rabbit (Orvctolagus cumiculus) population reinforcement? Eur $\mathrm{J}$ Wildl Res $54: 449-453$

Crawley MJ (2007) The R book. Wiley and Sons, New York

Delibes-Mateos M, Delibes M, Fenreras P, Villafuerte R (2008a) Key role of European rabbits in the conservation of the western Mediterranean basin hotspot. Conserv Biol 22(5):1106-1117

Delibes-Mateos M, Feneras P, Villafierte R (2008b) Rabbit (Onyctolagus cuniculus) abundance and protected areas in central-southem Spain: why they do not match? Eur J Wildl Res 55(1):65-69

Delibes-Mateos M, Ferreras P, Villafuerte R (2008c) Rabbit populations and game management: the situation after 15 years of rabbit haemorrhagic disease in central-southern Spain. Biodivers Conserv $17: 559-574$

Delibes-Mateos M, Ferreras P, Villafuerte R (2009) European rabbit population trends and associated factors: a review of the situation in the Iberian Peninsula. Mamm Rev 39(2):124-140

Fa JE, Sharples CM, Bell DJ (1999) Habitat correlates of European rabbit (Oryctolagus cuniculus) distribution after the spread of RVHD in Cadiz province, Spain. J Zool 249:83-96
Fletcher D, Mackenzie D, Villouta E (2005) Modelling skewed data with many zeros. A simple approach combining ordinary and logistic regression. Environ Ecol Stats 12:45-54

Gálvez-Bravo L, Belliure J, Rebollo S (2009) European rabbits as ecosystem engineers: warrens increase lizard density and diversity. Biodivers Conserv 18:869-885

Gea-Izquierdo G, Muñoz-Igualada J, San Miguel-Ayanz A (2005) Rabbit warren distribution in relation to pasture communities in Mediterranean habitats: consequences for management of rabbit populations. Wildl Res $32: 1-9$

González LM, San Miguel A (Coord.) (2004) Manual de buenas prácticas de gestión en fincas de monte mediterráneo de la red Natura 2000. DG Biodiversidad. Mínisterio de Medio Ambiente. Madrid

Kolb HH (1985) The burrow structure of the European rabbit (Oryctolagus cuniculus L.). J Zool 206:253-262

Lombardi L, Fernández N, Moreno S, Villafuerte R (2003) Habitatrelated differences in rabbit (Orvctolagus cuniculus) abundance, distribution and activity. $J$ Mammal $84(1): 26-36$

Lombardj L, Fernández N, Moreno $S$ (2007) Habitat use and spatial behaviow in the European rabbit in three Mediterranean environments. Basic Appl Ecol 8:453-463

Muṽoz J (2005) Fomento del conejo de monte (Onctolagus cuniculus) en ecosistemas mediterráneos de suelos ácidos: ecología de madrigueras, selección y utilización de pastos y repoblaciones con conejos. PhD Thesis. Universidad Politécnica de Madrid. Madrid. Spain

Palomares F (2001) Conparison of 3 methods to estimate rabbit abundance in a Mediterranean environment. Wild Soc Bull 29:578-585

Palomares F (2003) Warren building by European rabbits (Orvctologus cuniculus) in relation to cover availability in a sandy area. $\mathrm{J}$ Zool 259:63-67

Palomares F, Calzada J, Revilla E (1996) El manejo del hábitat y la abundancia del conejo: diferencias entre dos hábitats potencialmente idénticas. Rev For 9:201-210 
Pech RP, Sinclair ARE, Newsome A, Catling PC (1992) Limits to predator regulation of rabbits in Australia: evidence from predator removal experiments. Oecologia 89:102-112

R Development Core Team (2008) R: A language and environment for statistical computing, reference index version 2.8.0. R Foundation for Statistical Computing, Vienna, Austria. ISBN 3-90005107-0, URL http $/ /$ www.R-project.org

Rogers PM, Myers KJ (1979) Ecology of the European wild rabbit, Onctolagus cuniculus in Mediterranean habitats. I. Distribution in the landscape of the Coto Donana, S Spain. J Appl Ecol 16: $691-703$

Virgós E, Cabezas-Díaz S, Lozano J (2007) Is the endemic wild rabbit (Oryctolagus cuniculus) an endangered species in Spain? Sociological constraints in the conservation of species. Biodivers Conserv 16:3489-3504

Williams D, Acevedo P, Gortazar C, Escudero MA, Labarta JL, Marco J, Villafuette R (2007) Hunting for answers: rabbit (Orvctolagus cuniculus) population trends in notheastem Spaim. Eur J Wildl Res 53:19-28 